\title{
The impact of visual impairment on nutritional status: A systematic review
}

\author{
Nabila Jones and Hannah Bartlett
}

Aston University, UK

\begin{abstract}
The aim of this review was to evaluate the literature that has investigated the impact of visual impairment on nutritional status. We identified relevant articles through a multi-staged systematic approach. Fourteen articles were identified as meeting the inclusion criteria. The sample size of the studies ranged from 9 to 761 participants. It was found that visual impairment significantly affects nutritional status. The studies reported that visually impaired people have an abnormal body mass index (BMI); a higher prevalence of obesity and malnutrition was reported. Visually impaired people find it difficult to shop for, eat, and prepare meals. Most studies had a small sample size, and some studies did not include a study control group for comparison. The limitations of these studies suggest that the findings are not conclusive enough to hold true for only those who are visually impaired. Further studies with a larger sample size are required with the aim of developing interventions.
\end{abstract}

\section{Keywords}

Activities of daily living, food experiences, eating patterns, nutrition, shopping, visual impairment

\section{Introduction}

Nutritional status is defined as the 'intake of a diet sufficient to meet or exceed the needs of the individual, that will keep the composition and function of the otherwise healthy individuals within normal range' (Jeejeebhoy, Detsky, \& Baker, 1990). Poor nutritional status has been reported to be caused by three main factors: decreased intake of nutrients, altered utilisation, and increased requirements (Jeejeebhoy et al., 1990). Nutritional status is considered as an important determinant of successful ageing (Dahany et al., 2014), and perception of quality of life has been reported to be affected by poor nutritional status (Johansson, Bachrach-Lindstrom, Carstensen, \& Ek, 2009).

Recent reports carried out in the United Kingdom suggest that the needs of visually impaired people to maintain good nutritional status are not being met. A report, My Voice, stated that 61\% of the visually impaired, always or frequently, needed support to prepare meals (Slade, 2015). A UK organisation, DisabledGo, working on behalf of the government and local authorities, reported that only $23 \%$ of restaurants produce menus in large print for those with visual impairment (DisabledGo, 2014). They further stated that not accommodating those with disabilities is costing the economy 249 billion pounds (DisabledGo, 2014).

We previously reported that older adults with age-related macular degeneration (ARMD) consume fewer calories than is recommended for their age (Stevens, Bartlett, \& Cooke, 2015). In addition, they are unclear about what foods or supplements they should consume (Stevens et al., 2015). Due to the ageing population, the number of people living with visual impairment in the United Kingdom is rising. Around 79\% of people living with sight loss are over the age of 64 (Government 
Office for Science, 2016). One in every three people aged 85 and over is living with sight loss (RNIB, 2016).

Many studies have reported the importance of the role of vision and visual cues when eating (Barkeling, Linne, Melin, \& Rooth, 2003; Burger, Cornier, Ingebrigtsen, \& Johnson, 2011; Linne, Barkeling, Rossner, \& Rooth, 2002; Renner, Sproesser, Stok, \& Schupp, 2016; Scheibehenne, Todd, \& Wansink, 2010; Wadhera \& Capaldi-Phillips, 2014; Wansink, Painter, \& North, 2005); yet the literature relating to the impact of sight loss on nutritional status is limited. To date, the impact of severe sight impairment on nutritional status has not been researched in the United Kingdom. A search for previous literature reviews, concerning the impact of visual impairment on nutritional status, using the search terms 'nutrition' and 'visual impairment' found reviews relating to how poor nutrition can contribute to ocular disease (Wu et al., 2014); however, no review has been performed to date, looking at the impact of visual impairment on nutritional status.

This review aims to evaluate and compare the findings of the literature that has investigated the impact of visual impairment on nutritional status.

\section{Methods}

\section{Search strategy}

We identified the relevant articles that evaluated visual loss and nutritional status published in journals through a multi-staged, systematic approach. In the first stage, a computerised search of Web of Science, Science Direct, Wilson, and PubMed database was performed to identify all relevant articles. Terms and words used for the search included 'visual impairment', 'visual loss', 'sight loss', 'blindness', and 'sight impaired'; these were then separately used in combination with search terms 'nutrition', 'shopping', 'eating patterns', 'activities of daily living', 'Mini Nutritional assessment (MNA)', 'food experiences', and 'nutritional screening tools'. Google scholar was also searched using the same search guidelines, and bibliographies of the retrieved articles were manually searched. Only studies conducted on human subjects were included.

In the second stage, all abstracts were examined to identify articles that

1. Researched how visual impairment affects experiences of restaurant use, meal preparation, and shopping.

2. Included information relating to how visual impairments affect activities of daily living (ADLs) or feeding and eating development in the young.

3. Commented on the effects of visual impairment on body mass index (BMI) or on studies that carried out nutritional screening or analysed the nutritional intake of visually impaired people.

In the third stage, full-text articles were reviewed according to the inclusion and exclusion criteria shown below, and relevant articles were incorporated into the manuscript. 


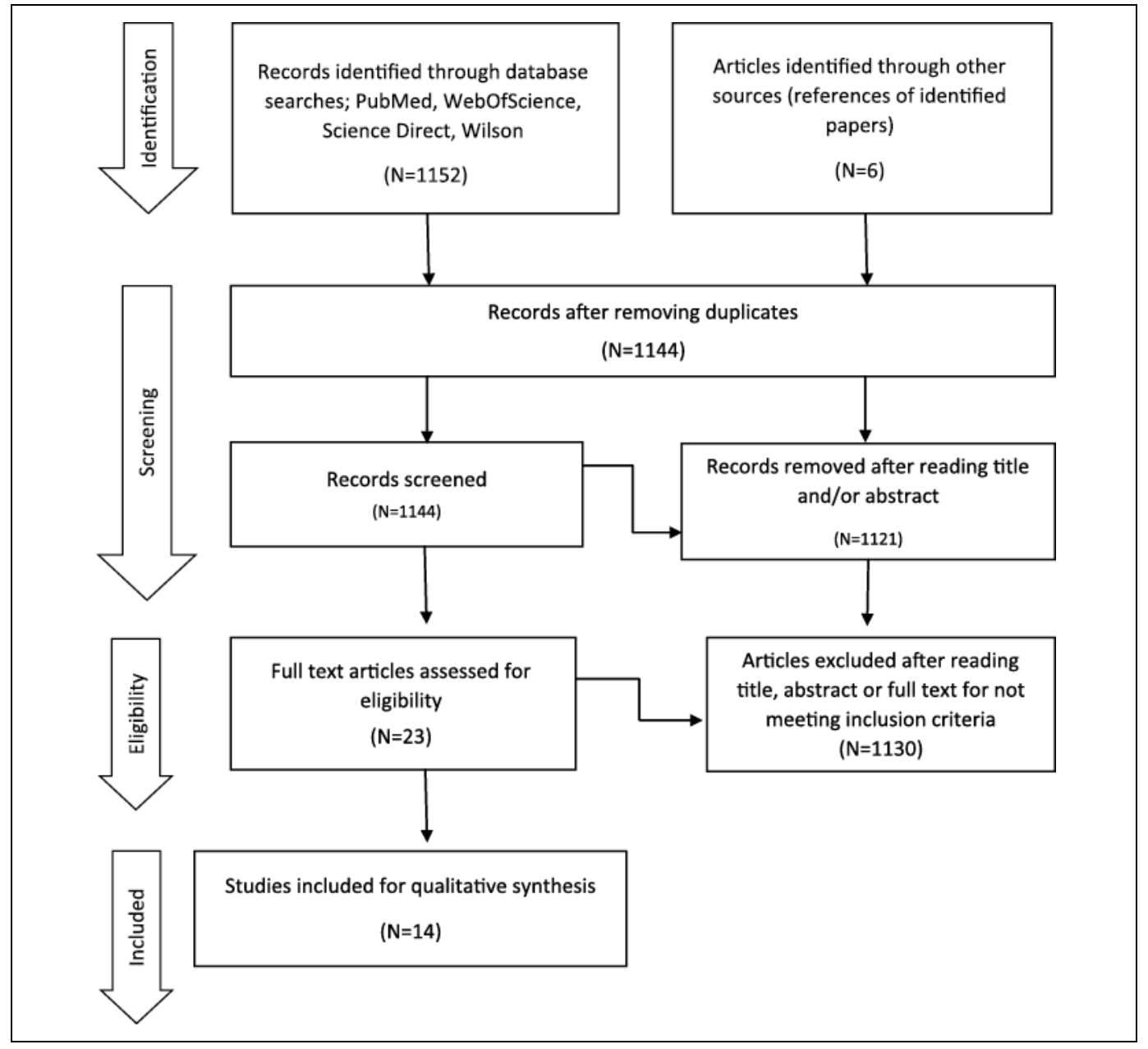

Figure 1. Protocol for literature review.

\section{Criteria for inclusion and exclusion}

Studies were included if they commented on factors affecting nutritional status, such as undernutrition, obesity, diet, and BMI. They were also included if they researched eating patterns/behaviours/experiences or commented on food-related obstacles for the visually impaired, such as shopping, eating, and preparing meals and restaurant use.

Letters to editors and conference presentations were excluded. Articles commenting on how nutritional status contributes to ocular diseases, such as the need for supplements for ARMD or other diseases that can cause visual impairment, were excluded. Articles that looked at how poor nutritional status can exacerbate ocular disease, such as the effects of BMI on cataract progression and type, were excluded. Fourteen articles were included in this review (see Figure 1).

\section{Data extraction}


We grouped the studies into two categories: those that were qualitative and those that were quantitative. We ordered the articles according to the year they were published (ascending order). The results were tabulated according to author, date, country; age; sample size (gender) (including number of visually impaired and sighted in each study); type of visual impairment; methods used; key findings; and implications for future research (see Table 1).

\section{Evaluation of studies}

We used the 16-item Quality Assessment Tool for Studies With Divers Design (QATSDD), designed for systematic reviews. The QATSDD complies with the preferred reporting criteria for systematic reviews set out by Liberati, Tetzlaff, Altman, and PRISMA Group ((Liberati et al., 2009); Augestad \& Jiang, 2015). It has been reported to have good validity and reliability.(Sirriyeh, Lawton, Gardner, \& Armitage, 2012). It can be applied to both qualitative (14 items) and quantitative studies (14 items). Each item can be given a maximum score of 3 with a total score of 42 (Sirriyeh et al., 2012). The percentage score of each paper was calculated by dividing the total sum of each paper by 42. We used a previously employed method (Augestad \& Jiang, 2015) to rate the quality of the paper as 'high quality $\geq 75 \%$ ', 'good $=50 \%-75 \%$ ', and poor $<25 \%$.

\section{Results}

\section{Study characteristics}

We identified 14 articles for inclusion in this review. Six articles were qualitative, and eight were quantitative (see Table 1). The studies were carried out across 11 countries. Most of the studies were cross-sectional in design. It was found that most studies did not use a sample size that was representative of the population. Only six studies included more than 100 participants (de Faria, da Silva, \& Ferreira, 2012; Gopinath, Liew, et al., 2014; Burlutsky, \& Mitchell, 2014; Kostyra, Zakowska-Biemans, Sniegocka, \& Piotrowska, 2017; Magdalena, Urzedowicz, Motylewski, Zeman, \& Pawlicki, 2016; Montero, 2005; Muurinen et al., 2014), the rest included less than 60. The studies were carried out with participants with an age range of 3 months to $>90$ years. The demographic range in some of the studies was also narrow; some studies (Bilyk, Sontrop, Chapman, Barr, \& Mamer, 2009) had a higher level of female participation (Baker, 2006; Muurinen et al., 2014; Nakamura et al., 1999). Some were restricted to a particular setting or geographical area, that is, one school (Acil \& Ayaz, 2015); therefore, the results cannot be generalised to the population. The classification of visual impairment was not consistent across the studies, some used gross methods (Muurinen et al., 2014) to classify participants as visually impaired, and others carried out sight tests or used standardised classification (Nakamura et al., 1999). There was a great variation in the cause of visual impairments; some reasons given were ocular trauma, optic nerve hypoplasia to condition unknown. Most studies did not use a control group as a comparison for the study, and therefore, it is difficult to conclude that their findings only hold true for visually impaired people. 
Table 1. Characteristics of the 14 research articles reviewed.

\begin{tabular}{|c|c|c|c|c|c|c|}
\hline \multicolumn{7}{|l|}{ alitative studies } \\
\hline $\begin{array}{l}\text { Date of publication } \\
\text { (reference) country }\end{array}$ & Age & Sample size (gender) & Type of visual impairment & Methods & Authors key findings (QATSDD score) & $\begin{array}{l}\text { Implications for future research as reported } \\
\text { by author }\end{array}$ \\
\hline $\begin{array}{l}\text { January 2006 (Baker, 2006) } \\
\text { United States }\end{array}$ & $20-80$ years & $\begin{array}{l}21 \text { participants (females } \\
15 \text {, males } 6 \text { ) }\end{array}$ & $\begin{array}{l}\text { Varying degrees of visual } \\
\text { impairment (congenital } \\
\text { blindness and acquired sight } \\
\text { loss) }\end{array}$ & Interviews & $\begin{array}{l}\text { Consumer normalcy is achieved through } \\
\text { distinction in the marketplace. Four dimensions } \\
\text { revealed as important in those with visual } \\
\text { impairment are achieving distinction and presence } \\
\text { in the marketplace ('I am here', 'I am me'), } \\
\text { competence ('I am in control'), and equality ('I } \\
\text { belong'). } \\
\text { (GOOD) }\end{array}$ & $\begin{array}{l}\text { Future research into the temporal aspects of } \\
\text { consumer normalcy is warranted, that is, } \\
\text { observation of what visually impaired } \\
\text { consumers learn over time. }\end{array}$ \\
\hline $\begin{array}{l}\text { Spring } 2009 \text { (Bilyk, Sontrop, } \\
\text { Chapman, Barr, \& Mamer, } \\
\text { 2009) Canada }\end{array}$ & $\begin{array}{l}30+\text { to } \leq 50 \\
\text { years }\end{array}$ & 9 (females 4 , males 5) & $\begin{array}{l}\text { Severely sight impaired and } \\
\text { blind since age } 5\end{array}$ & $\begin{array}{l}\text { Semi-structured in-depth } \\
\text { interviews }\end{array}$ & $\begin{array}{l}\text { Nutrition and blindness professionals must work } \\
\text { together to reduce food-related obstacles in the } \\
\text { visually impaired. } \\
\text { (GOOD) }\end{array}$ & $\begin{array}{l}\text { Social structure and skill development of the } \\
\text { visually impaired need to be investigated } \\
\text { according to the needs identified for } \\
\text { shopping, food preparation, and restaurant } \\
\text { use by this study. The implications of the } \\
\text { dislike of cooking and physical activities } \\
\text { need to be investigated. }\end{array}$ \\
\hline $\begin{array}{l}\text { December } 2011 \text { (de Faria, da } \\
\text { Silva, \& Ferreira, 2012) } \\
\text { Brazil }\end{array}$ & - & $\begin{array}{l}224 \text { ( } 21 \text { for focus groups) } \\
203 \text { questionnaire } \\
\text { respondents }\end{array}$ & $\begin{array}{l}\text { Total visual impairment } \\
\text { (blind) }\end{array}$ & $\begin{array}{l}\text { Focus groups and } \\
\text { questionnaire }\end{array}$ & $\begin{array}{l}\text { Ideal restaurant profile for those who are visually } \\
\text { impaired is one where menu is read by server, } \\
\text { empathetic servers, round tables, low music, and } \\
\text { lighting. Server should be summoned by a button. } \\
\text { (HIGH) }\end{array}$ & $\begin{array}{l}\text { Allows insight into the factors that need to } \\
\text { be addressed for the visually impaired using } \\
\text { restaurants }\end{array}$ \\
\hline $\begin{array}{l}\text { November } 2014 \text { (Smyth, } \\
\text { Spicer, \& Morgese, 2014) } \\
\text { United States }\end{array}$ & $\begin{array}{l}3 \text { months-3 } \\
\text { years }\end{array}$ & $\begin{array}{l}30 \text { (females } 13 \text {, males } \\
17 \text { ) }\end{array}$ & $\begin{array}{l}\text { Tactual learners (no light } \\
\text { perception) and visual } \\
\text { learners (20/70 to 20/180) } \\
\text { teller acuity }\end{array}$ & $\begin{array}{l}\text { Semi-structured video } \\
\text { interviews }\end{array}$ & $\begin{array}{l}\text { Improving caretaker confidence can promote } \\
\text { independence at mealtimes, and can potentially } \\
\text { minimise difficulties in establishing good eating } \\
\text { habits in visually impaired children. } \\
\text { (GOOD) }\end{array}$ & $\begin{array}{l}\text { Mainly participants of optic nerve } \\
\text { hypoplasia were used in this study. This } \\
\text { diagnosis can have medical implications that } \\
\text { affect eating abilities and need to be } \\
\text { researched in future. } \\
\text { Studies determining implementation } \\
\text { protocols that promote family-centred } \\
\text { practices need to be carried out. }\end{array}$ \\
\hline $\begin{array}{l}\text { June } 2015 \text { (Acil \& Ayaz, } \\
\text { 2015) Turkey }\end{array}$ & $\begin{array}{l}10.43 \pm 2.88 \\
\text { years }\end{array}$ & $\begin{array}{l}74 \text { (females } 36 \text {, males } \\
\text { 38) }\end{array}$ & $\begin{array}{l}\text { Acquired and congenital sight } \\
\text { loss (partial and complete) }\end{array}$ & $\begin{array}{l}\text { Questionnaire and physical } \\
\text { assessment }\end{array}$ & $\begin{array}{l}\text { The children who were visually impaired were } \\
\text { mainly obese or overweight, and they showed } \\
\text { poor nutritional habits skipping meals ( } 58.1 \% \text {; } \\
\text { mainly lunch). } \\
\text { (GOOD) }\end{array}$ & $\begin{array}{l}\text { Findings convey that health of children in } \\
\text { the visually impaired population should be } \\
\text { monitored. Children who are visually } \\
\text { impaired are at higher risk of health } \\
\text { problems than those without. }\end{array}$ \\
\hline $\begin{array}{l}\text { March } 2017 \text { (Gladstone et al., } \\
\text { 2017) Malawi }\end{array}$ & $<6$ years & $\begin{array}{l}42 \text { participants in total } \\
\text { (11 females, } 9 \text { males } \\
\text { took part in interviews) } \\
10 \text { home observations ( } 2 \\
\text { females and } 8 \text { males) and } \\
22 \text { took part in focus } \\
\text { groups, gender }\end{array}$ & $\begin{array}{l}\text { Low vision and blind } \\
\text { participants }\end{array}$ & $\begin{array}{l}\text { In-depth interviews, focus } \\
\text { groups, } 10 \text { home } \\
\text { observations }\end{array}$ & $\begin{array}{l}\text { Parents require support to meet their children's } \\
\text { developmental needs. Professional training is } \\
\text { required to support careers of those with visual } \\
\text { impairment and challenge community stigma. } \\
\text { (HIGH) }\end{array}$ & $\begin{array}{l}\text { Future research will need to analyse the } \\
\text { feasibility of undertaking child development } \\
\text { training packages. }\end{array}$ \\
\hline \multicolumn{7}{|l|}{ Quantitative studies } \\
\hline $\begin{array}{l}\begin{array}{l}\text { Date of publication } \\
\text { (reference) country }\end{array} \\
\text { (efor }\end{array}$ & Age & Sample size (gender) & Type of visual loss & Methods & Authors key findings & Implications for future research \\
\hline $\begin{array}{l}\text { April } 1999 \text { (Nakamura et al., } \\
\text { 1999) Japan }\end{array}$ & 64-95 years & $\begin{array}{l}7 \text { visually impaired } \\
\text { (females } 28,9 \text { males) } 42 \\
\text { control subjects }\end{array}$ & $\begin{array}{l}\text { physically handicapped } \\
\text { persons handbook Grades } 1 \text { to } \\
6\end{array}$ & $\begin{array}{l}\text { Activity of daily livings } \\
\text { assessed by nurse using } \\
\text { physical Self-Maintenance } \\
\text { scale } \\
\text { Semi-structured interview } \\
\end{array}$ & $\begin{array}{l}\text { Those with visual impairment significantly had } \\
\text { difficulty shopping. } \\
\text { (GOOD) }\end{array}$ & $\begin{array}{l}\text { A larger study is required to see that there } \\
\text { are clear significant differences between } \\
\text { complex activities in those with visual } \\
\text { impairment and those without. }\end{array}$ \\
\hline
\end{tabular}




\section{March 2014 (Gopinath, \\ Liew, et al., 2014)}

\section{Australia}

May/June 2014 (Muurinen et Mean age 83 years

al., 2014) Finland

November 2015 (Pardhan, Latham, Tabrett, \& Timm 2015) United Kingdom

\section{$81 \pm 10$ years 14}

visually

75 years \pm 5

75 years \pm
healthy

healthy
subjects

August 2016 (Magdalena, Urzedowicz, Motylewski, Zeman, \& Pawlicki, 2016)
Poland Poland

February 2017 (Kostyra, Zakowska-Biemans, males)

162 females, 79 250 (153 females, 97 males)

Blind and partially sighted

Congenitally blind and acquired sight loss causin
Central visual field los (ARMD participants)

Unable to read regular prin with/without spectacles
Central visual field los

Three 24-hr food diaries re-

demographic and

ss than adequed participere to the non-disabled

population. There is a higher risk of obesity and

potential for ill health in the visually impaired

(GOOD)

Information of visual status High prevalence of being overweight and obese in Socioeconomic conditions and family cas obtained from medical $\begin{array}{ll}\text { records and health care } & \text { High-fat intake found. Dietary consumption } \\ \text { workers. Face-to-face } & \text { patterns were the same as those who are not }\end{array}$ children than those who are not visually impaired. histories may account for the findings of interviews: Three 24-hr visually impaired.

food surveys. (GOOD)

measurements (BMI), diet

quality assessment using

the KIDMED index.

Physical activity (hour per

watching TV recorded

Face-to-face interviews,

anthropometric

measurements (BMI)

assessment of ADLs using

the OARS ADL scale.

The MNA nutritional

screening, tool structur

questionnaire, medical

records, and anthropo

measurements (BMI)

Movement kinematics

compared using three-

dimension motion ana

Three tasks: eating,

drinking, and turning a key

in a lock were measured.

Those with AMD have significantly more difficulty shopping and preparing meals than

ability in those with and without AMD. adults with AMD in order for them to

Those with vision impairment were older females. A longitudinal study would be useful in the They were malnourished according to MNA. Anthropometric data (BM)
and demographic survey

Questionnaire data analysed using SPSS They also had lower BMI than those withou vision impairment.

(GOOD)

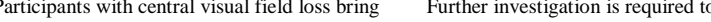
objects closer (glass to pour drink), need to make determine if rehabilitation can improve the more corrections (more stabs of a fork to grasp food). They do not perform common daily living tasks as efficiently as healthy subjects do. (GOOD)

Excessive body mass and abdominal obesity are an urgent health problem in children with visual impairmen

\section{(GOOD)}

( impaired. Shopping choices were affected by status. many opting for online shopping. Restaurant many opting for online shopping. Restaur impaired were supported. contrast effects the rete required to see if The pouring contrast to tasks of a higher contrast.

The factors attributing to high levels of need to be investigated. develop solutions for nutrition-related A

Further ind loss, or if they have a threshold. participants' contrast sensitivity than other

The findings in this study should be used to 


\section{Nutritional status}

BMI. Visual impairment was reported to be significantly linked with abnormal BMI. Obesity in males (Magdalena et al., 2016; Roebothan, 1999) and school children was reported (Acil \& Ayaz, 2015; Magdalena et al., 2016; Montero, 2005). It was attributed to reduced physical activity in some studies (Magdalena et al., 2016) or excess food consumption in others (Roebothan, 1999). One study reported that the finding of obesity in males was not significant (Magdalena et al., 2016). Undernutrition and low body weight were reported in females (Muurinen et al., 2014; Roebothan, 1999). It was identified in one study that females were not meeting the daily recommended intake of milk products, grains, and meats. Males were also reported to consume less than adequate amounts of milk products (Roebothan, 1999). Another study reported females as overweight and obese, but it was found that even they did not consume as much fats, carbohydrates, and proteins as males (Montero, 2005).In this study, males were mainly categorised as obese and females as overweight (Montero, 2005). Some studies reported a higher prevalence of obesity in the visually impaired; however, they did not assign their findings to any gender (Acil \& Ayaz, 2015; Bilyk et al., 2009). The findings of high rates of obesity in males and malnutrition in females were also reported in a conference abstract which did not meet the inclusion criteria to include in the main results table (Vági, Deé, Lelovics, \& Lakatos, 2012). One longitudinal study used BMI data as part of its study; however, it did not report the data in their final findings (Gopinath, Liew, et al., 2014).

Eating and meal preparation. The ease of eating meals was self-reported by the participants to be unaffected by visual impairment in two studies (Gopinath, Liew et al., 2014; Nakamura et al., 1999). A purely objective study however reported that when speed was measured using three-dimension motion analysis, those with visual loss, eat and drink more slowly, require cutlery closer to them, and make more corrections when eating and drinking (Pardhan, Latham, Tabrett, \& Timmis, 2015). This finding is of interest as it has been previously reported that when cutlery is closer to a person, they consume more food (Wadhera \& Capaldi-Phillips, 2014). Many studies did not research meal preparation in visually impaired people, those that did extracted similar themes (Bilyk et al., 2009; Kostyra et al., 2017). They found that meal preparation was a great obstacle for visually impaired people, to the point where they reported it as an aversion (Bilyk et al., 2009). They reported that boiling and cutting tasks were very difficult (Bilyk et al., 2009; Kostyra et al., 2017). The study with a larger sample size was able to provide more information (Kostyra et al., 2017). They reported that dinner preparation could take up to two hours, and $23 \%$ of respondents stated that it could take even longer than this. They also found that visually impaired people purchased ready-to-eat products such as cheese and meat products, but they rarely purchased frozen fruits and vegetables. They were also able to report tasks that visually impaired people did not find difficult, such as sandwich preparation and washing foods.

Restaurants. Restaurant use was reported to be a great obstacle across the studies evaluated (Bilyk et al., 2009; de Faria et al., 2012; Kostyra et al., 2017). Those with larger sample sizes provided a detailed analysis with regard to shopping and restaurant use and were able to extract more themes (de Faria et al., 2012; Kostyra et al., 2017) than those that did not (Bilyk et al., 2009). The studies all reported that visually impaired people felt more comfortable eating in restaurants where staff were helpful, empathic, and did not treat them as a burden (Bilyk et al., 2009; de Faria et al., 2012; Kostyra et al., 2017). In one study, over a quarter of visually impaired people stated that they frequently visited snack bars (Kostyra et al., 2017). They reported that availability of braille, large print menus, or audio would also be of great help (Bilyk et al., 2009; de Faria et al., 2012; Kostyra et al., 2017). Additionally, the possibility of being assisted by their guide dog in restaurants would be helpful (Bilyk et al., 2009; Kostyra et al., 2017). Another finding was that visually impaired people prefer low-intensity light and music, round tables, and being able to summon a server with a buzzer (de Faria et al., 2012).

Shopping. Many studies reported shopping as difficult for visually impaired people (Baker, 2006; Bilyk et al., 2009; Gopinath, Liew, et al., 2014; Kostyra et al., 2017; Nakamura et al., 1999). Being able to read labels (Yu, Tullio-Pow, \& Akhtar, 2015), being able to shop predictably, that is, buying food items from the same shelves, and staff assistance, were stated as requirements for an ideal shopping experience (Bilyk et al., 2009; Kostyra et al., 2017). It was reported that visually impaired people purchased the same brands for years (Kostyra et al., 2017). Food freshness and low meat fat content were conveyed to be very important factors in determining food choices (Kostyra et al., 2017). The main source of obtaining food was from the local grocers, and one third of people were reported to shop online (Kostyra et al., 2017). One study focused solely on shopping experiences of the visually impaired, and although the sample size was small, it was able to provide detailed qualitative analysis of the participant's needs (Baker, 2006). It reported that in order for visually impaired people to achieve consumer normalcy, they need to be recognised as in control, as an individual, a presence, and someone who belongs to the marketplace. 
Development of feeding. Two studies researched the impact of visual impairment, on the feeding and eating development, of young children and infants (Gladstone et al., 2017; Smyth, Spicer, \& Morgese, 2014). They both came to the same conclusion that caretaker confidence can promote independence at mealtimes and can potentially minimise difficulties in establishing good eating habits (Gladstone et al., 2017; Smyth et al., 2014).

Nutritional status screening and nutrition intake analysis. Nutritional screening is normally carried out using a nutritional screening tool (Donini, Savina, Rosano, \& Cannella, 2007). These tools are useful, as they are used to assess those who require further nutritional assessment. Nutritional screening using the MNA nutritional screening tool was conducted in one study (Muurinen et al., 2014). It was found that visually impaired older females were more malnourished than those who were not. Another study grossly categorised the food groups visually impaired people were consuming into milk products, meats, and grains (Roebothan, 1999). They reported reduced intake of milk products in visually impaired people. Another study reported that only $36.4 \%$ of visually impaired people consider nutritional value when making food choices (Kostyra et al., 2017). It was found that obese and overweight visually impaired school children were consuming higher than recommended levels of fats and fewer carbohydrates (Montero, 2005). Although many studies stated that poor dietary habits (Acil \& Ayaz, 2015; Bilyk et al., 2009; Magdalena et al., 2016; Muurinen et al., 2014; Nakamura et al., 1999) were affecting nutritional status, not many carried out or provided a detailed analysis of actual nutrition intake or the calories that were consumed by visually impaired people. One study highlighted that male school children were consuming almost double the recommended intake of calories. Males were consuming $2604 \mathrm{kcal} / \mathrm{day}$, and females $2159 \mathrm{kcal} / \mathrm{day}$ (Montero, 2005). In this study, it was found that $88.2 \%$ of those with visual impairment had a very poor diet or a diet which needed improvement (Montero, 2005). These findings highlight the importance of the need for nutritional screening in visually impaired people.

\section{Discussion}

The studies carried out convey that being visually impaired significantly impacts nutritional status. A high incidence of obesity has been reported in visually impaired people, particularly among children and males. Females were found to be more malnourished and consuming less than the recommended daily intake. In some studies and in those they were reported to be overweight or obese however, they were still consuming less than their male counterparts were. Despite being carried out in different countries, settings, and across different age ranges, the findings in these studies were repeatable.

Visually impaired people find shopping, meal preparation, and restaurant use very difficult. It has been reported that many visually impaired people do not shop independently and prefer to purchase food online as it is convenient (Kulyukin, 2010; Terry \& Childers, 2009). Their experiences in the marketplace would be improved by receiving adequate support and if they are not treated as a burden. The studies reported that visually impaired people prefer predictability, for example, that they had 'learned shopping'. A trend of going to the same aisles for the same foods was safe. This was highlighted as a detriment in one study as the participants were unaware that healthier options existed, such as pre-prepared salad. If they knew these foods existed, they would make more informed food choices.

Concerning restaurant use, more than one study reported that visually impaired people felt like a burden. In describing their ideal restaurant experience, a repeatable finding was that they would like the menu to be read to them. They also stated that they would prefer a bell, round tables, and large print or braille menus.

The duration of preparing meals ( $>2 \mathrm{hr}$ ) and the difficulty of boiling and cutting foods were highlighted in the studies. Eating was found to be difficult, particularly in older adults with visual impairment. A purely objective study looking at central visual field loss (CFL) showed that mobility and dexterity were reduced. Participants with CFL demonstrated significantly longer overall movement times. They had shorter minimum viewing distance. For two of the three ADLs tasks set (eating and drinking), they needed more corrections in movement (Pardhan et al., 2015). A study using the (MNA) tool found older adults with visual impairment to be more malnourished than those without (Muurinen et al., 2014).

High rates of obesity were found in visually impaired children of school age; this was attributed to poor food choices and lack of exercise. An interesting finding was that visually impaired individuals did not perceive their disability as an obstacle. They believed that it was their lack of motivation and exercise that inhibited them from taking care of themselves (Bilyk et al., 2009). One study stated that perhaps visually impaired individuals have a less negative attitude towards being overweight. It stated that they may have an innate desire towards a more robust stature (Roebothan, 1999). Another study reported that as they could not see or get any satisfaction from their appearance, they were not concerned by it (Bilyk et al., 2009). An interesting finding was that just over a third of visually impaired people take an interest in the nutritional value of food before purchasing.

In studies that looked at younger children with visual impairment, it was reported that caretaker confidence can promote independence at mealtimes and can potentially minimise difficulties in establishing good eating habits (Smyth et al., 2014). This can be done by providing parents with professional training. They reported that 
providing adaptations for an individual's visual needs, encouraging sensory experiences around food, and teaching developmental expectations in children are necessary (Smyth et al., 2014).

From this review, it is evident that the impact of visual impairment on nutritional status is significant; it is necessary to investigate the effect of visual impairment on nutritional status in the UK population.

\section{Limitations}

The sample size of some studies was small (Baker, 2006; Bilyk et al., 2009; Gladstone et al., 2017;; Nakamura et al., 1999; Pardhan et al., 2015; Roebothan, 1999; Smyth et al., 2014). There was sample bias in two studies, in that the participants were selected from services they approached or because they used regularly (de Faria et al., 2012; Gladstone et al., 2017). There was gender bias towards females, in the sample selection of some studies (Baker, 2006; Muurinen et al., 2014; Nakamura et al., 1999). One study reported the use of a non-probabilistic sample (de Faria et al., 2012). There was a narrow demographic range in some studies, that is, some ages (Bilyk et al., 2009), and also some ethnicities were not represented due to geographic location (Smyth et al., 2014). One study selected its participants from a single setting, a school; (Acil \& Ayaz, 2015). These findings indicate that the results of some studies cannot be generalised to the visually impaired population. Nearly all the studies were of a cross-sectional design. The studies did not have similar methods, and all classified visual impairment differently. There were a number of reasons for the cause of sight loss cited in the studies, from congenital blindness, acquired from ocular disease to ocular trauma. One study used gross methods to define visual impairment (Muurinen et al., 2014). Some did not use a control group of normal sighted people, where if they had, it would provide more information and support a cause-effect finding (Bilyk et al., 2009; Kostyra et al., 2017; Roebothan, 1999). In some studies reporting accuracy from participants (Roebothan, 1999) and the researchers interpretation of what the participants reported may have influenced the results (Bilyk et al., 2009), and therefore, accurate conclusions may not be drawn.

\section{Conclusion}

The 14 studies evaluated in this review convey that visual impairment significantly affects nutritional status. Most studies reported that future studies should be carried out with a larger sample size. Some stated that it would be useful to see the temporal effects of visual impairment on the factors that they measured, that is, conducting longitudinal studies (Baker, 2006; Muurinen et al., 2014). This review has highlighted the lack of nutritional screening for those with visual impairment both globally and in the United Kingdom.

Importantly, the studies carried out convey that there is a great need to develop interventions to support the nutritional status of visually impaired people. These interventions could take the form of skill development (Bilyk et al., 2009), rehabilitation interventions for the elderly, to maintain independence (Gopinath, Liew, et al., 2014) or developmental training packages to support parents of those children with visual impairment (Gladstone et al., 2017).

\section{Funding}

The author(s) received no financial support for the research, authorship, and/or publication of this article.

\section{References}

Acil, D., \& Ayaz, S. (2015). Screening of visually impaired children for health problems. Asian Nursing Research, 9, 285290. doi:10.1016/j.anr.2015.06.004

Augestad, L. B., \& Jiang, L. (2015). Physical activity, physical fitness, and body composition among children and young adults with visual impairments: A systematic review. British Journal of Visual Impairment, 33, 167-182. doi:10.1177/0264619615599813

Baker, S. M. (2006). Consumer normalcy: Understanding the value of shopping through narratives of consumers with visual impairments. Journal of Retailing, 82, 37-50. doi:10.1016/j.jretai.2005.11.003

Barkeling, B., Linne, Y., Melin, E., \& Rooth, P. (2003). Vision and eating behavior in obese subjects. Obesity Research, 11, 130-134. doi:10.1038/oby.2003.21

Bilyk, M. C., Sontrop, J. M., Chapman, G. E., Barr, S. I., \& Mamer, L. (2009). Food experiences and eating patterns of visually impaired and blind people. Canadian Journal of Dietetic Practice and Research, 70, 13-18. doi:10.3148/70.1.2009.13

Burger, K. S., Cornier, M. A., Ingebrigtsen, J., \& Johnson, S. L. (2011). Assessing food appeal and desire to eat: The effects of portion size \& energy density. International Journal of Behavioral Nutrition and Physical Activity, 8, Article 101. doi:10.1186/1479-5868-8-101

Dahany, M. M., Drame, M., Mahmoudi, R., Novella, J. L., Ciocan, D., Kanagaratnam, L., . . Jolly, D. (2014). Factors associated with successful aging in persons aged 65 to 75 years. European Geriatric Medicine, 5, 365-370. doi:10.1016/j.eurger.2014.09.005

de Faria, M. D., da Silva, J. F., \& Ferreira, J. B. (2012). The visually impaired and consumption in restaurants. International Journal of Contemporary Hospitality Management, 24, 721-734. doi:10.1108/09596111211237264 
DisabledGo. (2014). DisabledGo Study 2014. Retrieved from http://www.disabledgo.com/blog/2014/12/ disabledgo-study-shocks-the-government-with-evidence-of-inaccessible-british-high-streets/\#.WJNnZeKLTIU

Donini, L. M., Savina, C., Rosano, A., \& Cannella, C. (2007). Systematic review of nutritional status evaluation and screening tools in the elderly. Journal of Nutrition Health \& Aging, 11, 421-432.

Gladstone, M., McLinden, M., Douglas, G., Jolley, E., Schmidt, E., Chimoyo, J., . . Lynch, P. (2017). “Maybe I will give some help . . . maybe not to help the eyes but different help": An analysis of care and support of children with visual impairment in community settings in Malawi. Child: Care, Health and Development, 43, 608-620. doi:10.1111/cch.12462

Gopinath, B., Liew, G., Burlutsky, G., \& Mitchell, P. (2014). Age-related macular degeneration and 5-year incidence of impaired activities of daily living. Maturitas, 77, 263-266. doi:10.1016/ j.maturitas.20l3.12.001

Government Office for Science. (2016). Future of an aging population. Retrieved from https://www.gov.uk/government/uploads/system/uploads/attachment_data/file/535187/gs-16-10-future-of-an-ageingpopulation.pdf

Jeejeebhoy, K. N., Detsky, A. S., \& Baker, J. P. (1990). Assessment of nutritional-status. Journal of Parenteral \& Enteral Nutrition, 14, S193-S196.

Johansson, Y., Bachrach-Lindstrom, M., Carstensen, J., \& Ek, A.-C. (2009). Malnutrition in a home-living older population: Prevalence, incidence and risk factors. A prospective study. Journal of Clinical Nursing, 18, 1354-1364. doi:10.1111/j.1365-2702.2008.02552.x

Kostyra, E., Zakowska-Biemans, S., Sniegocka, K., \& Piotrowska, A. (2017). Food shopping, sensory determinants of food choice and meal preparation by visually impaired people. Obstacles and expectations in daily food experiences. Appetite, 113, 14-22. doi:10.1016/j.appet.2017.02.008

Kulyukin, V. K. A. (2010). Accessible shopping systems for blind and visually impaired individuals: Design requirements and the state of the art. The Open Rehabilitation Journal, 3, 158-168.

Liberati, A., Altman, D. G., Tetzlaff, J., Mulrow, C., Gotzsche, P. C., Ioannidis, J. P., . . Moher, D. (2009). The PRISMA statement for reporting systematic reviews and meta-analyses of studies that evaluate healthcare interventions: explanation and elaboration. BMJ, 339, b2700. doi: 10.1136/bmj.b2700

Linne, V., Barkeling, B., Rossner, S., \& Rooth, P. (2002). Vision and eating behavior. Obesity Research, 10, 92-95.

Magdalena, W., Urzedowicz, B., Motylewski, S., Zeman, K., \& Pawlicki, L. (2016). Body mass index and waist-to-height ratio among schoolchildren with visual impairment: A cross-sectional study. Medicine, 95(32). doi:10.1097/md.0000000000004397

Montero, P. (2005). Nutritional assessment and diet quality of visually impaired Spanish children. Annals of Human Biology, 32, 498-512. doi:10.1080/08014460500142744

Muurinen, S. M., Soini, H. H., Suominen, M. H., Saarela, R. K. T., Savikko, N. M., \& Pitkala, K. H. (2014). Vision impairment and nutritional status among older assisted living residents. Archives of Gerontology and Geriatrics, 58, 384-387. doi:10.1016/j.archger.2013.12.002

Nakamura, K., Otomo, A., Maeda, A., Kikuchi, S., Motohashi, Y., Tanaka, M., . . Y Yamamoto, M. (1999). Evaluation of complex activities in daily living of elderly Japanese with visual impairment. Aging-Clinical and Experimental Research, $11,123-129$.

Pardhan, S., Latham, K., Tabrett, D., \& Timmis, M. A. (2015). Objective analysis of performance of activities of daily living in people with central field loss. Investigative Ophthalmology \& Visual Science, 56, 7169-7178. doi:10.1167/iovs.1516556

Renner, B., Sproesser, G., Stok, F. M., \& Schupp, H. (2016). Eating in the dark: A dissociation between perceived and actual food consumption. Food Quality and Preference, 50, 145-151. doi:10.1016/j.foodqual.2016.02.010

Royal National Institute of Blind People. (2016). State of the Nation Eye Health Report. Retrieved from https://www.rnib.org.uk/sites/ default/files/RNIB-State-of-the-Nation-2016-APDF\%20format.PDF

Roebothan, B. V. (1999). Preliminary assessment of nutritional status in a group of persons with visual impairments. Nutrition Research, 19, 1731-1740. doi:10.1016/s0271-5317(99)00128-1

Scheibehenne, B., Todd, P. M., \& Wansink, B. (2010). Dining in the dark. The importance of visual cues for food consumption and satiety. Appetite, 55, 710-713. doi:10.1016/j.appet.2010.08.002

Sirriyeh, R., Lawton, R., Gardner, P., \& Armitage, G. (2012). Reviewing studies with diverse designs: The development and evaluation of a new tool. Journal of Evaluation in Clinical Practice, 18, 746-752. doi:10.1111/j.1365-2753.2011.01662.x

Slade, J. (2015). My Voice 2015. Retrieved from https://www.rnib.org.uk/sites/default/ files/My\%20Voice\%20UK\%20Report-FINAL_0.PDF

Smyth, C. A., Spicer, C. L., \& Morgese, Z. L. (2014). Family voices at mealtime: Experiences with young children with visual impairment. Topics in Early Childhood Special Education, 34, 175-185. doi:10.1177/0271121414536622

Stevens, R., Bartlett, H., \& Cooke, R. (2015). Dietary analysis and nutritional behaviour in people with and without age-related Macular disease. Clinical Nutrition, 10, e112-e117.

Terry, L., \& Childers, C. K.-S. (2009). Expanding oppurtunities for online shoppers with disabilities. Journal of Business Research, 62, 572-578.

Vági, Z., Deé, K., Lelovics, Z., \& Lakatos, É. (2012). Nutritional status of blind and visually impaired patients. Zeitschrift für Gastroenterologie, 50(5), A82. doi:10.1055/s-0032-1312436

Wadhera, D., \& Capaldi-Phillips, E. D. (2014). A review of visual cues associated with food on food acceptance and consumption. Eating Behaviors, 15, 132-143. doi:10.1016/j.eatbeh.2013.11.003

Wansink, B., Painter, J. E., \& North, J. (2005). Bottomless bowls: Why visual cues of portion size may influence intake. Obesity Research, 13, 93-100. doi:10.1038/oby.2005.12 
Wu, H., Zhang, H., Li, P., Gao, T., Lin, J., Yang, J., . . Ye, J. (2014). Association between dietary carbohydrate intake and dietary glycemic index and risk of age-related cataract: A meta-analysis. Investigative Ophthalmology \& Visual Science, 55, 3660-3668. doi:10.1167/iovs.13-13695

Yu, H., Tullio-Pow, S., \& Akhtar, A. (2015). Retail design and the visually impaired: A needs assessment. Journal of Retailing and Consumer Services, 24, 121-129. doi:10.1016/j.jretconser.2015.03.001 